\title{
TEMAS, CONCEITOS E PROCESSOS EM EDUCAÇÃO POPULAR: UMA DISCUSSÃO A PARTIR DAS CIÊNCIAS SOCIAIS
}

Felipe Ziotti Narita**

\begin{abstract}
RESUMO: Este artigo discute proposições e possibilidades de entendimento da educação popular a partir de formulações teóricas do campo das ciências sociais. Tratase de situar a discussão da educação popular no conjunto mais amplo de problemas lançados pelas ciências sociais, analisando as práticas educativas à luz de processos sociopolíticos, sobretudo, a partir de referenciais sociológicos e históricos (democratização política, cidadania, modernização). Por meio da exposição e da discussão de alguns dos conceitos e abordagens que vinculam a educação popular a temas mais amplos das ciências sociais, o texto argumenta que o entendimento da educação popular, para além das discussões curriculares e de conteúdo, deve ser teoricamente inserido na investigação dos próprios impasses sociais, políticos e econômicos que acompanham a América Latina nas últimas cinco décadas.
\end{abstract}

Palavras-chave: Educação popular; Modernização; Democracia; Ciências Sociais; Políticas públicas.

ABSTRACT: This paper discusses propositions and possibilities of understanding popular education in dialogue with theoretical formulations from social sciences. This topic suggests a constelation of problems and concepts in order do think a close association between educational practices and themes dealing with historical and sociological references (democratization, citizenship, modernization). The paper argues that popular education must be situated in theoretical terms in the very core of the social and political impasses throughtout the last 50 years in Latin America.

Keywords: Popular education; Modernization; Democracy; Social Sciences; Public policiy.

É sempre difícil discutir uma "teoria" da educação popular, uma vez que o próprio objeto comporta inúmeras ambiguidades. Além disso, sendo inseparável das diversas práticas que modelam seu entendimento, a questão fica ainda mais insólita: nesse sentido, muito pouco há em comum, por exemplo, entre o que

\footnotetext{
* Artigo baseado em palestra proferida na XLII Semana de BioEstudos, realizada em agosto de 2014 na Faculdade de Filosofia, Ciências e Letras de Ribeirão Preto - Universidade de São Paulo (USP).

** Doutorando em História pela Universidade Estadual Paulista "Júlio de Mesquita Filho" (Unesp) - Campus de Franca. Bolsista CAPES. Professor credenciado junto ao Programa de PósGraduação em Planejamento e Análise de Políticas Públicas (Unesp). Pesquisador do grupo "Políticas públicas para o desenvolvimento social" (CNPq/Unesp). E-mail: fznarita@gmail.com
} 
figuras e "teorias" tão diversas como a educação llustrada de um Simón Rodríguez, a orientação anarquista de Elisée Réclus, o comunismo de Bukharin e as concepções de um Freinet, entre meados do século XIX e o início do XX, chamavam de "educação popular" (CAMBI, 1999; NARITA, 2013; ZALAZAR, 2010) e o que, no século XXI, fóruns, cursinhos, conselhos, educadores, redes e escolas entendem por este termo. Sobretudo na América Latina contemporânea, o tratamento teórico da questão fica ainda mais complexo se assumimos alguns diferenciadores sociológicos como educação do campo, educação de adultos, educação indígena etc.

De partida, fundamental é reconhecer que a pluralidade de expressões e experiências no campo da educação popular na América Latina assinala, além de situações provenientes das trajetórias históricas nacionais, sentidos diversos para as ações em educação. Malgrado essa notável pluralidade de formas, contudo, acredito que um fio condutor estrutura o campo da educação popular como conjunto de demandas históricas no continente: o reconhecimento de assimetrias socioeconômicas. Nesse sentido, se podemos pensar em algum nível de generalização teórica para a discussão da educação popular latinoamericana, arrisco dizer que, das escolas zapatistas no México e das importantes experiências durante a revolução sandinista na Nicarágua à vertente venezuelana do movimento Fé e Alegria (presente em boa parte da América Latina a partir dos anos 1960 e 1970), o reconhecimento das abruptas clivagens socioeconômicas que grassam o continente (aprofundadas a partir dos amplos processos de modernização dos anos 1950) constitui uma relação estrutural para orientação das práticas educativas.

É justamente na abertura da forma educativa a processos sociais que Oscar Jara (2010) apontou como matriz fundamental da reflexão em educação popular latinoamericana a busca por uma racionalidade ético-emancipadora, de modo que as práticas em educação popular atuam justamente como elementos de mudança social no sentido de um exercício crítico sobre as próprias relações econômicas, sociais e políticas da região. Proponho, antes de qualquer "teoria", algumas linhas para discussão da educação popular à luz de temas alçados pelas ciências sociais, especialmente a sociologia e a história, demarcando 
possibilidades de entendimento das formas educativas (espaço, currículo, ensino etc.), no contexto da educação popular, a partir de processos sociais abrangentes das próprias configurações históricas latino-americanas.

Francisco Vio Grossi (1984), nesse sentido, propõe alguns parâmetros de entendimento da educação popular como processos educativos inseridos em transformações estruturais, sobretudo em função do sem-número de distorções socioeconômicas historicamente implicadas no desenvolvimento do capitalismo latino-americano. Grossi busca uma fundamentação, sobretudo, política para a educação popular, delimitando que
A tarefa da educação popular é contribuir para o desenvolvimento da consciência do povo a respeito das reais causas dos problemas encontrados a fim de aumentar a capacidade de mobilização por meio da participação em organizações, apoiando-as (GROSSI, 1984, p. 307, tradução minha). ${ }^{1}$

À parte o discreto veio verticalizado do processo de consciência na abordagem de Grossi, vale reter que a forma educativa emerge do próprio cotidiano (day-to-day activities), ou seja, de práticas concretas e socialmente situadas, conforme a interpretação pragmática depreendida pelo autor a partir da tríade piagetiana da ação-reflexão-ação. Grossi, basicamente, vincula a educação popular a uma atitude crítica em relação aos modelos de capitalismo dependente na América Latina. Não quero, aqui, adentrar o tema das teorias da dependência: o que interessa é a alterativa que o autor deriva desse entendimento, ou seja, trata-se de sinalizar a possibilidade de alternativas para um modelo democrático efetivamente participativo, buscando uma distribuição mais equitativa de acesso a bens culturais.

A própria expressão "educação popular", aliás, carrega diversos significados. Uma primeira aproximação seria a demarcação, grosso modo, de formas, práticas e métodos que se afastam dos currículos e formas escolares predominantes e oficiais, recortando, dentro do genérico termo "popular",

\footnotetext{
1 "The task of popular education is to contribute to the development of people's consciousness concerning the real causes of the problems that they encounter, in order to increase their capacity to mobilize themselves by participating in organizations and supporting them" (GROSSI, 1984).
} 
estratos da população menos abastados em termos socioeconômicos. Partindo do princípio de que a ampla escolarização e os modernos sistemas escolares, construídos no ocidente entre os séculos XIX e XX, justamente eram dirigidos às grandes massas, a demarcação, dentro dos processos educativos, de um campo para a educação "popular" evidencia indícios de que as demandas históricas dos processos de ensino não são efetivamente supridas. Conforme observa o sociólogo Jacobo Waiselfisz (1985), a própria delimitação do entendimento da "educação popular" a partir desses balizamentos iniciais demarca, para além do problema da nomenclatura, profundas diferenças em relação ao sentido das práticas propostas. Nessa chave analítica, o tema da educação popular implica formas alternativas dentro do processo educativo - portanto, um contexto diferencial cujas especificidades, antes de repousarem nas práticas e nos conteúdos, indicam significativos vetores socioeconômicos, culturais e políticos para seu entendimento.

Em muitos casos, inclusive, situando-se em uma esfera de educação nãoformal (descoladas, portanto, de prerrogativas oficiais sobre a composição de currículos, por exemplo), diversas experiências em educação popular constroem uma autêntica esfera participativa, com discussões de temas públicos entrelaçados a conceitos e conteúdos formalizados no currículo localmente elaborado e contextualizado (KATO, 2007). Especialmente no Brasil contemporâneo, diversas experiências de educação popular estão diretamente vinculadas a importantes polos universitários (em diversos municípios do estado de São Paulo, por exemplo, há cursos abastecidos por universidades como Unicamp, Unesp, UFSCar e USP), o que configura a educação popular como espaço para formação inicial e continuada de docentes (VERRANGIA, 2013). Griff Foley (1998) afirma que as próprias dinâmicas participativas em relação a conteúdos (seja por meio de discussões, mesas redondas, situações-problema etc.) situa a educação popular como possibilidade de constituição de coletivos que, para além do ensino pautado em "vencer" os conteúdos, criticamente e coletivamente refletem sobre problemas e temas relevantes. Trata-se, a rigor, de uma proposta de expansão do conhecimento escolar para setores socioeconomicamente desfavorecidos, efetivando a possibilidade de uma 
autêntica esfera pública, construindo e ampliando o estatuto social do saber a partir da proposição que Derrida (2001) dirigiu como autêntica profissão de fé institucional no saber acadêmico-escolar: a incondicional liberdade organizacional de uma esfera pública aberta ao argumento e ao debate.

Colocado como movimento no campo educacional latino-americano, o tema da educação popular é diretamente relacionado às teorias da modernização e às diversas dimensões abertas por estas no campo do desenvolvimento social. Lidando com vários déficits referentes à efetivação da educação escolar, a educação popular, como esfera de debate e reflexão sobre os próprios sistemas de ensino formais (sustentados tanto pelas escolas privadas quanto pelas escolas públicas), permite um direcionamento das práticas educativas a partir de uma visada crítica, no sentido de uma reflexão sobre os limites da razão e dos sentidos da educação escolarizada no conjunto social. Até que ponto, por exemplo, as prerrogativas de formação de mão-deobra qualificada ou de desenvolvimento "crítico" da cidadania de fato correspondem às realizações da educação escolar? Tentarei desdobrar alguns elementos dessa discussão ao longo do texto. Por ora, importa reter que, antes de qualquer crítica interna à própria forma escolar (seja como crítica de conteúdos ou de sistemas avaliativos, por exemplo), muitas investigações sugerem a inclusão da educação escolar em uma visão de conjunto das transformações sociais.

O sofisticado historiador Germán Rama (1978), também importante nome da sociologia da educação na América Latina, analisava as importantes implicações da incorporação das massas nos sistemas educativos especialmente a partir dos anos 1950, problematizando-as no conjunto mais amplo das transformações atravessadas pelas diversas sociedades no continente. A base do conhecido argumento de Rama era o entendimento de que a expansão e a diferenciação da estrutura socioeconômica alimentam dinâmicas de mobilidade social, correspondendo a anseios de formação de mãode-obra qualificada, sistema escolar e expansão de cursos superiores. Processos marcados, portanto, em contexto de abrupta urbanização e 
substituição de importações, com a definição e o desenvolvimento nos campos do setor produtivo e dos serviços.

A bem da verdade, as transformações sinalizadas por Germán Rama como um delineamento da teoria da modernização nas sociedades latinoamericanas a partir de processos educativos implicavam a ideia de uma espécie de fuite en avant, ou seja, um processo de modernização social capaz de controlar pressões em favor de mudanças estruturais, mantendo relações de classe e de poder. O sistema educacional e as demandas historicamente correlatas de formação, nesse contexto, seriam uma espécie de mecanismo generativo incumbido de transformar as pressões de grupos ascendentes em expectativas institucionalizadas de mobilidade social. As diversas formas educativas, desdobrando o argumento, gravitam em torno de uma necessidade societal de reprodução. Aqui, a educação, entendida como sistema integrado de necessidades que devem ser supridas para a manutenção da organização social, adquire um viés funcional, correspondendo à busca por equilíbrio em estruturas sociais, com o predomínio de uma função central que articula dimensões sociais externas dentro das demandas do sistema de educação.

Trabalhando em um nível de abstração que permite generalizações para as dinâmicas históricas na América Latina, as teses de Germán Rama são muito importantes pois demonstram os vínculos teóricos entre educação e estrutura social em contextos de desenvolvimento socioeconômico acentuado configuração com a qual a América Latina lidou nas últimas cinco décadas (em países como México, Brasil, Argentina, Chile, Colômbia e Uruguai as dinâmicas foram talvez ainda mais acentuadas). Gostaria, contudo, de tecer algumas problematizações às implicações teóricas deste influente argumento de Rama a partir das próprias pautas construídas pelas diversas reflexões em educação popular. A teoria certamente acreditava em uma espécie de redistributivismo das oportunidades de inserção social (uma espécie de "mobilidade ascendente"), em uma leitura muito marcada pela funcionalidade dos modelos de escolarização dentro do capitalismo latino-americano. A educação popular, contudo, coloca interrogações sobre o efetivo alcance dessas teses "integracionistas", como se a educação, alavancada pela modernização das estruturas sociais, galvanizasse 
processos corretivos para as desigualdades socioeconômicas em função da extensão efetiva de direitos sociais e políticos, além da plena capacitação de quadros profissionais.

A essa lógica quase "funcionalista" da integração dos mecanismos de educação, alguns teóricos sublinham o caráter popular da educação assumindo sua estreita vinculação, de partida, a programas políticos. Trata-se de um entendimento de que a educação para ser popular desvela um conteúdo central em sua ação: uma educação "libertadora", como se o "povo" fosse o porta-voz de um programa histórico capaz de reverter a lógica das próprias estruturas produtivas. Um importante filósofo lukacsiano como Mészáros (2008), por exemplo, demonstra a configuração social da educação derivando-a de mecanismos de "internalização" que construiriam uma aceitação ativa das estruturas de reprodução social. Nesse sentido, a função crítica do ensino dirigido a grupos "populares" estaria subordinada à produção de uma "contraconsciência" - revestida, portanto, de um conteúdo emancipador fundante de toda prática. Certamente, a obra de Mészáros é muito extensa e de profunda repercussão, sobretudo nos campos da Sociologia, da História e da Filosofia: uma análise mais profunda deveria levar em consideração justamente as análises da forma educacional à luz do conjunto das reflexões do autor húngaro. Contudo, para os propósitos destas breves reflexões sobre alguns significados e sentidos da prática em educação popular, acredito que a visão de Mészáros corre sempre o risco de tornar a educação popular refém de uma ação política instrumental, operando a torção e a homogeneização de conteúdos e estruturas curriculares em função do "pragmatismoo" de uma ação política.

Este ponto, aliás, é justamente o argumento destacado por Jacobo Waiselfisz ao discutir algumas implicações da própria reflexão sobre educação popular na América Latina à luz dos enfoques "libertadores":

O problema está no conjunto de interpretações esquemáticas situadas em relação ao problema da ideologia e das formas de dominação. Disso foram depreendidas, de forma mecânica, objetivos e estratégias de educação popular por simples oposição. Chegou a ser pensado que a educação popular atuaria de forma inversa à educação dominante, ensinando o 
que esta não permite. Assim, ainda que o problema era relativamente resolvido em nível de conteúdos transmitidos e setores aos quais eram dirigidos, persistiram formas autocráticas de transmissão do saber (WAISELFISZ, 1985, tradução minha). ${ }^{2}$

Antes de qualquer homogeneização das formas educacionais (seja de um ponto de vista puramente integrativo ou de uma perspectiva "libertadora"), diversas experiências em educação popular assinalam justamente uma preocupação com o público ao qual o ensino é dirigido - o que implica uma reflexão sobre a própria situação de exclusão socioeconômica e de incompletude das tarefas também incumbidas aos poderes públicos. É certamente nesse sentido que reside a importância de diversas experiências da educação popular dos anos 1960: no caso brasileiro, certamente um dos mais paradigmáticos do continente, a educação popular demarcou de forma clara as assimetrias e as distorções socioeconômicas no país, de modo que, uma vez desenvolvida a partir de experiências no campo da alfabetização, cultivando forte vínculo com a ação política, a educação popular foi impulsionada tanto com a atuação dos Movimentos de Cultura Popular (MCPs) quanto com as experiências de Paulo Freire, em um momento de profundas alterações demográficas, sociais e culturais (AGGIO; BARBOSA; COELHO, 2002; SCHWARZ, 1978) coexistindo com uma acelerada modernização no modelo nacional-estatista (REIS, 2014).

Já no caso das profundas mudanças sociopolíticas ocorridas na América Latina partir dos anos 1980 e 1990, especialmente diante dos processos de democracia política construídos no continente sobre os escombros dos governos militares, dos golpes e das linhas antidemocráticas na atuação de parte das esquerdas dos anos 1960 e 1970, a agenda de temas e problemas no vasto campo da educação popular sofreu alterações significativas. A emergência de movimentos sociais como formas propositivas de uma esfera pública

\footnotetext{
2 "El problema radica en el conjunto de interpretaciones esquemáticas que se dan en relación al problema de la ideología y de las formas de dominación. De allí se desprendieron, en forma mecánica, objetivos y estrategias de educación popular por simple oposición. Llegó a pensarse que la educación popular actuaría a la inversa de la educación dominante, enseñando lo que ésta no permite. Así, si bien el problema se vio relativamente resuelto a nivel de contenidos transmitidos y sectores a quienes se dirigen, persistieron las formas autocráticas de transmisión de saber" (WAISELFISZ, 1985).
} 
democrática, nesse sentido, projeta marcas importantes para os processos educativos. Tilman Evers (1984) indica que a atuação de diversos setores da sociedade civil a partir dos escombros dos autoritarismos da América Latina implica, também, uma proposição de autonomia de expressões da sociedade civil em relação a partidos políticos e instituições. Trata-se, fundamentalmente, da estruturação de novos campos de ação para o "político" (na linha de Norbert Lechner e Fernando Mires). A educação popular, como força mobilizadora de indivíduos, pode sinalizar uma prática socio-cultural centrada em sujeitos sociais: fato que, nos processos democráticos contemporâneos, incorporam os diversos sujeitos envolvidos (alunos, professores etc.) na construção da identidade de um mesmo movimento coletivo, agora efetivamente desenvolvido como instância de diálogo e reivindicação política. Em formações históricas como a brasileira, por exemplo, a dinâmica pode significar um contrapeso fundamental da sociedade civil na desestruturação da verticalização herdada de longas décadas de "modernização conservadora", abrindo caminho para o moderno e a autonomia de seus movimentos e organizações (VIANNA, 2011).

Embora possa estar vinculada a amplos programas estatais de modernização, como nos anos 1970 com as diversas experiências do Serviço Nacional de Aprendizagem (SENA), na Colômbia, e do MOBRAL, no Brasil, a educação popular como efetivo campo de experimentação de metodologias, currículos e políticas de gestão encontra espaço fundamental no âmbito da sociedade civil das jovens democracias do continente. Creio que é justamente nesse ambiente de revitalização dos movimentos sociais que a educação popular, situada em um contexto de democracia política, encontra canais de representação de pautas sobretudo políticas em fóruns, encontros e reuniões. Como expressão das movimentações sociais, a própria posição da educação popular vetorizada pelos interesses e diversidades da sociedade civil expõe estruturas e formas de vinculação do Estado democrático a uma sociedade que pode ser capaz de canalizar plataformas e interesses sociopolíticos (NOGUEIRA, 2004).

Como aponta Moacir Gadotti (2012), ao propor a investigação da educação popular como forma de uma educação social mais ampla, 
O fato de a educação social ter-se desenvolvido mais entre ONGs, OSCs e movimentos sociais e populares demonstra 0 fracasso do poder público em atender os setores mais empobrecidos. A sociedade civil precisa chegar, e chega mesmo, onde o estado normalmente não chega, sem desobrigar o Estado de sua responsabilidade para com a educação. Pelo contrário, Movimentos sociais e ONGs tem mobilizado a população para que ela exija o cumprimento do seu direito à educação.

Ao entender a educação popular como uma das contribuições mais significativas da América Latina para o pensamento pedagógico, Gadotti pretende, no limite, sustentar a educação popular como uma plataforma de política pública. As implicações desta assertiva poderiam ser desdobradas como um salto histórico para além da matriz "clássica" da educação popular concebida nos anos 1960, que tomava o tema como paradigma de uma educação orientada para a mudança social revolucionária. O historiador Mario Garcés (2006, p. 88) enfatiza que

Por essa mesma razão, de que não se trata de práticas alheias à Educação Popular, é que se devem reconhecer novos desafios educativos em meio a estas práticas. Entre outros, adquire, na minha opinião, particular importância reconhecer, valorizar e potencializar os "sentidos sociais" (ou melhor, talvez, os sentidos do público) que emergem dos movimentos sociais, como uma produção cultural chave para os processos de democratização. Aquilo que hoje se denomina "políticas públicas" não é assunto que compete puramente ao Estado, mas também à sociedade. Se a sociedade e os movimentos sociais não estão envolvidos na constituição do público, na lógica liberal, as políticas públicas inevitavelmente conduzirão a práticas do tipo tecnocrático, instrumental ou clientelista.

A ideia, aliás, sugere uma abertura dentro do modelo "institucionalista" das políticas públicas no sentido de uma participação da sociedade civil (DYE, 2011) orientada justamente por processos fragmentários, "moleculares", marcados por territorialidades e demandas específicas, sustentando importantes vetores de desenvolvimento comunitário e social. Como demonstram as 
importantes pesquisas de Liam Kane (2010) apoiadas pela Unesp e pela Carnegie Foundation, a educação popular articula de forma democrática várias esferas de ação na sociedade civil, construindo estruturas de coesão e identidade política nas pautas dos diversos sujeitos e espaços de educação. Não se trata, bem entendido, de um ressurgimento de pautas e agendas das grandes matrizes da educação popular nos anos 1960, mas da consciência dos novos significados que a própria reflexão em um contexto democrático coloca diante dos sujeitos. Penso a educação popular, portanto, a partir do ângulo mais amplo sugerido pelos sociólogos Bernardo Sorj e Danilo Martuccelli (2008) para a reflexão das dinâmicas que marcam a América Latina: no caso da educação, trata-se de investigar de que forma os processos em educação podem galvanizar temas e possibilidades de ação para sedimentar matrizes de coesão social a partir da virada mais ampla da democratização das relações sociais em boa parte do continente a partir dos anos 1990.

O vigor de diversas experiências como o IMDEC no México, o CANTERA na Nicarágua e o CEAAL (atuante em diversos países do continente) ilustram exatamente essa configuração de uma esfera democrática em torno da qual a educação popular atualmente pode gravitar. É justamente como forma dos movimentos sociais que a educação popular redimensiona e reestrutura suas próprias pautas como reivindicações e problemas políticos por excelência. Nesse contexto, a partir do momento em que espaços para pautas comuns são construídos (redes, fóruns, associações, publicações etc.) e a própria educação popular é concebida como um problema, esse tipo de reflexividade permite uma auto-compreensão da própria educação popular como um movimento social. Assim, creio que

[...] a Educação Popular deve ser concebida como um componente das dinâmicas dos movimentos sociais, componente que colabora nos processos de autoconsciência individual e coletiva; reforça os processos de autonomia e criação cultural; favorece o desenvolvimento de iniciativas que formulam e recriam permanentemente "o público" e, no meio destes processos, favorece também "o salto" da diversidade em direção aos processos inéditos e democráticos da unidade de nossos povos (GARCÉS, 2006, p. 89). 
À luz desses argumentos, a agenda de temas e desafios da educação brasileira é certamente enorme. Em 2012, em situações diferentes, dois diagnósticos em muitos sentidos convergentes, no campo da educação, foram proferidos pelos professores Mozart Neves Ramos (então membro do Conselho Nacional de Educação) e Vladimir Safatle (2012):3 parafraseando as falas de ambos, o Brasil lida com questões do século XXI, contando com uma escola do século XX e problemas do XIX. Contando com importantes centros de pesquisa e estruturas de graduação e pós-graduação que buscam excelência no plano internacional (daí a centralidade de temas como a internacionalização, a produção científica etc.), inseridos portanto junto às demandas do século XXI, o país convive com um sistema escolar estruturado no século $X X$ (sobretudo a partir dos anos 1940-50) que ainda carrega fantasmas do XIX - por exemplo, o problema do analfabetismo e do acesso à qualidade em educação. Obviamente, não se trata, aqui, de fazer tábula rasa dos inúmeros avanços acumulados, sobretudo, desde os anos 1980 junto às políticas educacionais: afinal, é à luz da Constituição mais democrática da história do país que estão situados os importantes marcos da LDB e dos PCN, as discussões sobre evasão, competências, inclusão e as políticas de ingresso, permanência e expansão do ensino superior - além de linhas de financiamento estudantil, das formas de acesso aos ensinos fundamental e médio etc. (PALMA FILHO, 2005; SAVIANI, 2008).

No entanto, é igualmente certo que, apesar dos avanços, um inegável mal-estar permeia o cenário educacional. O antropólogo Darcy Ribeiro (2008) certa vez definiu a conjuntura de maneira clara: existe de forma indisfarçada uma "marginalização cultural do letramento". O sistema escolar, veículo por excelência da transmissão de saberes, funciona sobre uma exclusão. Exclusão que certamente revela um quadro socioeconômico eivado de assimetrias de oportunidades e condições de vida. É notável que, em termos de políticas educacionais, a preocupação de diversos documentos oficiais gire em torno da

\footnotetext{
${ }^{3}$ Entrevista de Mozart Neves Ramos (UFPE) concedida a Alexandre Garcia no canal Globo News. Exibição: 08/11/2012.
} 
proposição de uma escola capaz de fomentar o exercício "crítico" da cidadania. Formar o "cidadão", aliás, é uma tópica que está estruturada nas preocupações das elites políticas desde o processo de construção do Estado nacional no Brasil do século XIX (então um Império). Se no oitocentos o entendimento do "cidadão" adquiria um conteúdo moral como rotinização de ações em uma ordem política - daí o "bom cidadão" (NARITA, 2014) -, o problema do cidadão e da cidadania na República brasileira (especialmente no fim do século $X X$ e início do $X X I$ ) adquire contornos diferentes. Conforme sugere o historiador José Murilo de Carvalho (2001), a construção da democracia brasileira a partir dos anos 1980, embora tenha acelerado importantes processos de construção de direitos políticos, civis e sociais, torna os preceitos formais das políticas e dos registros legais inacessíveis para boa parcela da população

A cidadania, nesse sentido, parece um caminho ainda inconcluso. $O$ próprio acesso à qualidade da educação é certamente um dos grandes obstáculos. A grande questão, creio, é até que ponto o sistema de ensino e, sobretudo, como tentei argumentar neste texto, as dinâmicas sociais que reverberam nos processos de educação conferem sentido e conteúdo para a não-efetividade das ambições dos documentos legais. As experiências e os cenários de desenvolvimento da própria educação popular atestam a centralidade desses processos sociais marcados pelas profundas desigualdades socioeconômicas no acesso a bens culturais, por exemplo. Nesse sentido, as importantes pesquisas conduzidas por Dulce Whitaker (2010) sobre educação popular apontam justamente que "a criação e expansão de cursinhos populares se insere num quadro geral de políticas públicas, ações afirmativas, luta contra desigualdades e preconceitos”.

O próprio critério da "cidadania" coloca um sem-número de problemas nessa discussão. O antropólogo James Holston (2013) estabelece um importante entendimento da cidadania como forma de mediação social. O critério de cidadania no Brasil, nesse raciocínio, estrutura a própria desigualdade. 0 enquadramento na própria formação histórica da república brasileira aponta duas dimensões correlatas: uma incorporação formal a uma comunidade política (Estado-nação) e a distribuição assimétrica de direitos - modelo que sincroniza 
a universalidade da incorporação pautada na desigualdade distributiva em relação a direitos (HOLSTON, 2013, p. 258). Daí o tema de uma disjunção social fundamental, abrindo os impasses formais da estrutura política aos impasses da própria "modernização" social desigual. A análise e suas consequências teóricas permitem situar as dinâmicas democráticas para além da cidadania política e das liberdades civis delas derivadas: modelos que esvaziam o sentido social e as disjunções dos processos de cidadania, obliterando suas dimensões socioculturais. Nesse sentido, a reflexão sobre cidadania está situada no núcleo dos processos de democratização, pois

[...] os processos e as práticas que definem a cidadania são inerentemente disjuntivos - não cumulativos, lineares ou distribuídos de maneira homogênea entre os cidadãos, mas sempre uma mistura de elementos progressivos e regressivos, desequilibrados, heterogêneos e corrosivos. Nessa visão, a democracia está necessariamente ligada a uma concepção mais ampla de cidadania, que vai além da esfera política, e sua avaliação está vinculada às complexidades das realizações da cidadania em contextos históricos específicos (HOLSTON, 2013, p. 398).

É justamente à luz dessa "inclusão pela desigualdade" que as assimetrias sociais mostram seus vínculos com os processos de educação. Bem entendido, a educação popular não é substituta nem a solução para os diversos problemas dos sistemas formais de ensino. A própria posição da educação popular como prática concreta localmente situada - portanto, difusa em territorialidades diversas - permite um diálogo mais estreito com anseios e perspectivas junto a grupos socioeconomicamente desfavorecidos em círculos comunitários. Configuração bastante diferente dos sistemas de ensino, encadeados estruturalmente nos quadros do Estado nacional. Em contextos democráticos, as experiências em educação popular (especialmente a partir da maleabilidade de um ensino "não-formal") certamente aprofundam caminhos possíveis, tanto no plano de metodologias de ensino alternativas, quanto na mobilização de sujeitos em relação a temas e a debates públicos. Nesse sentido, antes de mero corretivo, a educação popular pavimenta, sobretudo, caminhos para o 
protagonismo da sociedade civil em relação às disjunções e às assimetrias dos processos de modernização.

\section{REFERÊNCIAS BIBLIOGRÁFICAS}

AGGIO, Alberto; BARBOSA, Agnaldo; COELHO, Hercidia. Política e sociedade no Brasil: 1930-1964. São Paulo: Annablume, 2002.

CAMBI, Franco. História da Pedagogia. São Paulo: Editora UNESP, 1999.

CARVALHO, José Murilo de. Cidadania no Brasil: o longo caminho. Rio de Janeiro: Civilização Brasileira, 2001.

DERRIDA, Jacques. L’université sans condition. Paris: Galilée, 2001.

DYE, Thomas. Understanding public policy. Boston: Longman, 2011.

EVERS, Tilman. Identidade: a face oculta dos movimentos sociais. Novos Estudos CEBRAP, São Paulo, n. 4, 1984.

FOLEY, Griff. Clearing the theoretical ground: elements in a theory of popular education. International Review of Education, v. 44, 1998.

GADOTTI, Moacir. Educação popular, educação social, educação comunitária. In: CONGRESSO INTERNACIONAL DE PEDAGOGIA SOCIAL, n. 1, São Paulo, 2012. Anais do Congresso Internacional de Pedagogia Social. São Paulo: USP, 2012.

GARCÉS, Mario. Educação popular e movimentos sociais. In: PONTUAL, Pedro; IRELAND, Timothy. Educação popular na América Latina: diálogos e perspectivas. Brasília, DF: Edições MEC/Unesco, 2006.

GROSSI, Francisco Vío. Popular education: Latin American experience. International Review of Education, v. 30, 1984.

HOLSTON, James. Cidadania insurgente. São Paulo: Companhia das Letras, 2013.

JARA, Oscar. Educación popular y cambio social en America Latina. Community Development Journal, Oxford, v. 45, n. 3, 2010.

KANE, Liam. Community development: learning from popular education in Latin America. Community Development Journal, Oxford, v. 45, n. 3, 2010. 
KATO, Danilo Seithi. O significado pedagógico da contextualização para o Ensino de Ciências. 116 f. Dissertação (Mestrado em Educação) Universidade de São Paulo, Ribeirão Preto, 2007.

MÉSZÁROS, István. A educação para além do capital. São Paulo: Boitempo, 2008.

NARITA, Felipe Ziotti. Elisée Réclus: educação e sociedade. In: SILVA, Hilda Maria Gonçalves; OLIVIERA, Sheila Pimenta e. Educação e políticas públicas: desafios, reflexões e possibilidades. Franca: Edições FCHS-UNESP, 2013. p. 678-689.

O Século e o Império: tempo, história e religião no Segundo Reinado. Curitiba: Editora Prismas, Editora Appris, 2014. (Coleção Ciências Sociais)

NOGUEIRA, Marco Aurélio. Um Estado para a sociedade civil. São Paulo: Cortez, 2004.

PALMA FILHO, João Cardoso. Política educacional brasileira: educação brasileira numa década de incertezas. São Paulo: CTE, 2005.

RAMA, Germán. Educación, estructura social y estilos de desarrollo. Perspectivas (Unesco), Paris v. 8, n. 3, 1978.

REIS, Daniel Aarão. Ditadura e democracia no Brasil. Rio de Janeiro: Zahar, 2014.

RIBEIRO, Darcy. Utopia Brasil. São Paulo: Hedra, 2008.

SAFATLE, Vladimir. O que quebrará o país?. Carta Capital, São Paulo, 09 jul. 2012.

SAVIANI, Dermeval. História das ideias pedagógicas no Brasil. 2. Ed. Campinas: Autores Associados, 2008.

SCHWARZ, Roberto. Cultura e política: 1964-1969. In: SCHWARZ, Roberto. 0 pai de família e outros estudos. Rio de Janeiro: Paz e Terra, 1978.

SORJ, Bernardo; MARTUCCELLI, Danilo. O desafio latino-americano: coesão social e democracia. Rio de Janeiro: Civilização Brasileira, 2008.

VERRANGIA, Douglas. Os cursos pré-vestibulares populares enquanto espaços educativos e de formação docente. Revista Eletrônica Cadernos CIMEAC, Ribeirão Preto, v.3, n.2, 2013.

VIANNA, Luiz Werneck. A modernização sem o moderno. Rio de Janeiro: Contraponto, 2011. 
WAISELFISZ, Jacobo. Reflexiones sobre la investigación y la educación popular. In: GAJARDO, Marcela (org.). Teoría y práctica de la educación popular. Pátzcuaro: CREFAL-PREDE/OEA-IDRC, 1985.

WHITAKER, Dulce. Da "invenção" do vestibular aos cursinhos populares. Revista Brasileira de Orientação Profissional, Ribeirão Preto, v. 11, 2010.

ZALAZAR, Oscar. Simón Rodríguez: reforma del lenguaje y de la sociedad. In: ARPINI, Adriana María. Diversidad e integración en Nuestra America. Buenos Aires: Biblos, 2010. 